\title{
Intellectual decision-making system in the context of potentially dangerous nuclear power facilities
}

\author{
Alexander Danilov ${ }^{1}$, Vladimir Povarov ${ }^{2}$, Viktor Burkovsky ${ }^{1}$, Semen Podvalny ${ }^{1}$ and Konstantin Gusev ${ }^{1, *}$ \\ ${ }^{1}$ Voronezh State Technical University, 394026, Voronezh, Russia \\ ${ }^{2}$ Novovoronezh Nuclear Power Plant, 396072, Novovoronezh, Russia
}

\begin{abstract}
The article deals with intelligent operation decision support system under condition of potentially hazardous nuclear facilities. The proposed system is referred to the class of advising systems and does not make final decisions in case of deviations of parameters to be analyzed, but generates general ways to solve an encountered problem and issues a set of recommendations for the plant personnel. In the article a fuzzy logic tool is used as mathematic tool. Lessons learnt from operation of nuclear facilities demonstrate that existing critical components (parts, areas, welding joints) are subject to increased failure under conditions of high operational loads, including beyond design loads and negative environmental impact. Usually in that situation there is probability of equipment integrity failure, when the unit is at power, with severe defect downing. For instance, the coolant leak and potential development of initial penetration defect to critical dimensions. In other words, in fact, the final observable result is always one - formation and development of operational crack which jeopardizes design integrity of the component and, accordingly, seriously compromises the nuclear power unit operation. The proposed situational model is linked with real knowledge data base where generated situational pairs are stored. The expert system is used for knowledge data base formation. Actually the proposed system consists of two independent fuzzy systems. From mathematical tool point of view, the advantage of such systems combination is lack of defuzzification unit in the first system and fuzzification unit in the second one.
\end{abstract}

\section{Introduction}

Accidents happened over the past decades consistently lead to the conclusion that following the way of technical progress a man is exposed to higher risk. Thanks to enhancement of technosphere and medicine average longevity increased significantly. Technosphere, created to protect people against external impacts, nowadays becomes a source of danger: commercially operated units capacity is increasing, technologies are more sophisticated, there is increase of inter-effect between facilities, equipment operation more depends on human factor. Risks and accidents scale significantly extended.

With that in mind it is required to take measures to protect people and environment against hazard generated by technosphere - accidents on hazardous nuclear facilities. These measures are important along the whole life cycle of the plant but specifically at the stage of design. At this particular stage it is possible to significantly improve nuclear facility safety without hefty increase of costs. Usually hazard level of facility operating under standard conditions, stipulated by the design, is much lower than the hazard level under emergency conditions.

Provided that different accidents at highly dangerous facilities were analyzed, it is possible to identify a number of common causes: design errors, incorrect decisions about siting and plant operation modes, underestimation of personnel training, negligence and carelessness. But accidents analysis does not solve all problems. It is required not only to find out weakness in technological cycle but forecast development of events caused by an accident at hazardous facilities, shape management decisions required for risk minimization.

Present day decision-making support systems at nuclear facilities are based on mathematical statistics data with low degree of adaptation to changing parameters. Such systems are intended predominantly for analysis of data backlog and ineffectively manage with situations forecasting tasks. Based on analyses of modern decisionmaking support systems at nuclear facilities it is proposed to implement a comprehensive intelligent decision making support system based on fuzzy logics tool distinguished by availability of alternative actions of personnel at hazardous nuclear facilities.

\section{Parameters generation}

For intelligent operation decision support system implementation fuzzy situational pattern "situationsituation" type is proposed.

For input matrix elements data from multi-parameters continuous monitoring system of the plant critical

*Corresponding author: gussev_konstantin@mail.ru 
components, subject to risk of operational damage, is used [1].

The situational model incorporates three main blocks:

- conditions evaluation block (fuzzification);

- decision making block;

- block of output action (defuzzification) [2].

Provided that two linguistic variables for input and output data streams are introduced:

$$
X_{i}<\text { «oncentration», } T_{x},\left[0, P_{i}\right]>,
$$

$Y_{i}<$ «Level of emergency situation occurrence »,

$$
T_{y},[0,1]>\text {, }
$$

where $T_{x}=\{$ «small», «mean», «rather high», «high»\}, $T_{y}=$ \{«low», «mean», «rather high», «high», «dangerous»\}, and semantic rule, which introduces compliance with each fuzzy variable out of the set $T_{x}, T_{y}$ fuzzy set $\tilde{C}_{x i}$ and $\tilde{C}_{y i}$, shown on Figure 1. Type of the membership function is selected by data approximation results and in the form of the Gaussian function [3]:

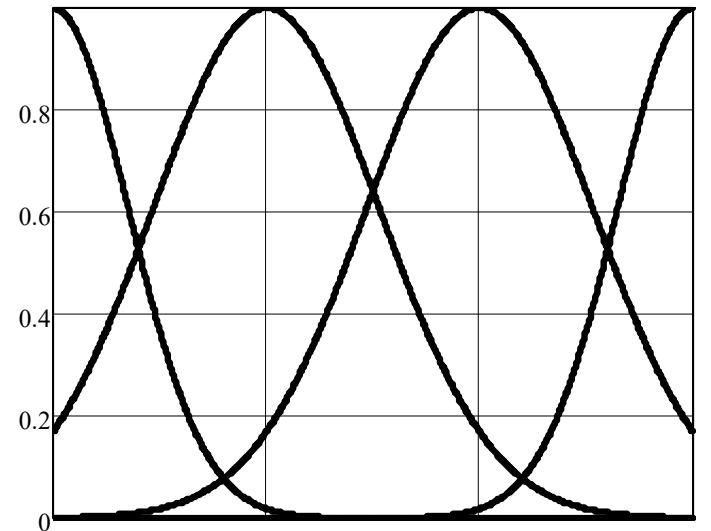

a)

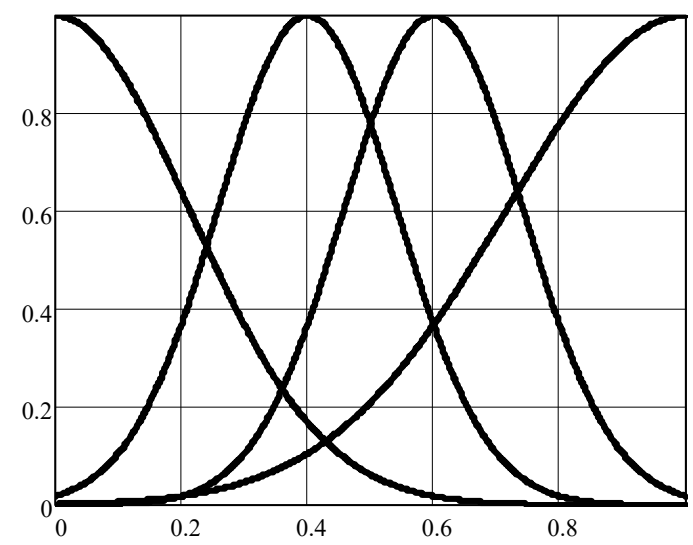

b)

Fig. 1. a) Membership function of fuzzy set $\tilde{C}_{x i}$; b) Membership function of fuzzy set $\tilde{C}_{y i}$.

$$
\mu\left(a_{i}\right)=\exp \left[-\left(\frac{a_{i}-x_{i}^{k}}{s_{i}^{k}}\right)^{2}\right]
$$

where $i=1, \ldots, n ; n$ - number of fuzzy model inputs while function parameters have the following interpretation: $x$ is a center, and $s$ is the width is the Gaussian curve.

\section{Model of decision making system}

Knowledge data base. In case of situational model implementation knowledge data base is a key block in making proper operational decision. The work uses static knowledge data base where pairs of matrix of the following type are stored:

\section{$<$ Current fuzzy situation $>-<$ Forecast fuzzy situation $>$.}

Fuzzy situation represents a matrix identical to matrix $S_{i}(n \times k), i=1, \ldots, l$, obtained in defuzzification block. Matrix $S$ is composed in the same way by means of the unit mentioned before and membership functions. The second element of the pair is a vector $\mathrm{S}_{i}(1 x k), i=1, \ldots, l$, obtained by means of linguistic variable $X$ and correspondent membership functions (Fig. 2). Thus, knowledge data base is in explicit form and presents a number of records in units of measurements ( $l \times 2)$.

In knowledge data base generation two main approaches were applied [4]:

1) generation of pairs in the knowledge data base based on historical data. At this stage reference situations, used in future for forecasting, are generated;

2) generation of pairs in the knowledge data base based on expert review of status of parameters being analyzed.

Decision making block. Within decision making procedure possible ratios for fuzzy situations are implemented. Equality extent is used in the work as a criteria for selection of closest situation from knowledge data base and, accordingly, corresponding outcome vector $S$ :

$$
\mu\left(S_{0}, S_{i}\right)=v\left(S_{0}, S_{i}\right) \& v\left(S_{i}, S_{0}\right),
$$

where $i=1, \ldots, k, \mu$ - equality degree of fuzzy situations, $v$ - degree of fuzzy situations introduction. In other words, situation obtained from input data and reference situation in knowledge data base are compared in this block.

It is proposed to apply the procedure of output vector $S$ generation depending on calculated equality degrees as follows:

\begin{tabular}{|c|l|}
\hline$\mu_{\max }>0,9$ & $\begin{array}{l}\text { Accept } \mathrm{S} \text { with the highest degree } \\
\text { of equality }\end{array}$ \\
\hline \multirow{3}{*}{$0,5<\mu_{\max }<0,9$} & $\begin{array}{l}\text { Select situation with three highest } \\
\text { degrees of equality and receive } \\
\text { result set } \mathrm{S} \text { by means of selected } \\
S=S_{\mu \max } \cap S_{\mu \max -i}, i=1, \ldots, 2 \\
\text { overlapping }\end{array}$ \\
\hline$\mu_{\max }<0,5$ & $\begin{array}{l}\text { Select situation with five highest } \\
\text { degrees of equality and receive } \\
\text { result set } \mathrm{S} \text { by means of selected } \\
S=S_{\mu \max } \cap S_{\mu \max -i}, i=1, \ldots, 4 \\
\text { overlapping }\end{array}$ \\
\hline
\end{tabular}

Block of output action. As a rule, algorithms of defuzzification are conducted in this block and a solution or likely recommendation is generated at the output. To improve quality of intelligent operation decision support 
system it is proposed to implement defuzzification process based on two situations: current and forecast. For this purpose it is proposed to use the block for assessment of the current state parameters. In the proposed block input parameters are changed into fuzzy set by means of linguistic variable $X_{i}<$ «oncentration», $T_{x},\left[0, P_{i}\right]>$.

Consequently, two fuzzy sets $S_{i}$ and $S_{0}$ enter decision making block input from forecasting block and correct status parameters evaluation block accordingly. At this stage for recommendations and likely solutions generation a set of fuzzy rules is applied:

$$
\text { IF } S_{0}=A \text { AND } S_{i}=B \quad T H E N R=Y .
$$

Data base of rules for the decision making process is generated based on expert evaluation of parameters and looks like in the Table 1.

Table 1. Data base of rules.

\begin{tabular}{|c|l|}
\hline $\begin{array}{l}\text { Level of emergency } \\
\text { occurrence risk }\end{array}$ & Personnel possible actions \\
\hline 1 & \multicolumn{1}{|c|}{2} \\
\hline Low & \multicolumn{1}{|c|}{ Steady conditions } \\
\hline Mean & $\begin{array}{l}\text { Continuous monitoring of the } \\
\text { situation and diagnostics of power } \\
\text { installation critical damage } \\
\text { parameters }\end{array}$ \\
\hline 1 & $\begin{array}{l}\text { Diagnostics, calculated and } \\
\text { experimental forecasting of event } \\
\text { development, maintenance and } \\
\text { restoration activities on operating } \\
\text { power unit }\end{array}$ \\
\hline Rather high & $\begin{array}{l}\text { Unit shutdown, maintenance } \\
\text { activities }\end{array}$ \\
\hline High & $\begin{array}{l}\text { Unit shutdown and decision making } \\
\text { about taking out of service }\end{array}$ \\
\hline
\end{tabular}

Thus, the result of the block of output action operation is a group of specific recommendations to be selected by the system depending on current and forecast values of the system parameters.
In the work defuzzification method with mean center is used:

$$
\bar{Z}=\frac{\sum_{i=1}^{k} \mu_{R}\left(Z_{i}\right) Z_{i}}{\sum_{i=1}^{k} \mu_{R}\left(Z_{i}\right)}
$$

where $Z_{i}$ is a point where function $\mu_{R}$ takes the maximum value [5].

Continuous multi-parameter monitoring system is able not only to analyze and generate parameters but also forecast the facility status. To improve quality of intelligent operation decision support system it is proposed to add a block for comparison of forecast values. Figure 2 [6] presents functional diagram of fuzzy situational model.

\section{Algorithm of decision making system operation}

Initial data of the algorithm represent a matrix of parameters to be analyzed. After identification of liguistic variables the pairs of fuzzy situations are generated.

First of all, based on available historical data and, secondly, relying on obrained expert data. As a result all pairs are combined in the common knowledge data base.

The structure of intelligent operation decision support system consists of two fuzzy models (Fig. 3):

- fuzzy situiational system represents fuzzy control «situation-action» [7]. Following formation of rules data base and knowledge data base fuzzy input set (fuzzyfication), designated by initial or current situation, are generated. After that the currect situation is compared with situations from knowledge data base and the biggest situation equiality degree is defined. Once maximum equiality degree is defined, the second value from the data base is selected, which are input data for fuzzy system.

- fuzzy system implements classical algorithm Mamdani except for fuzzyfication block, because fuzzy set enters the input.

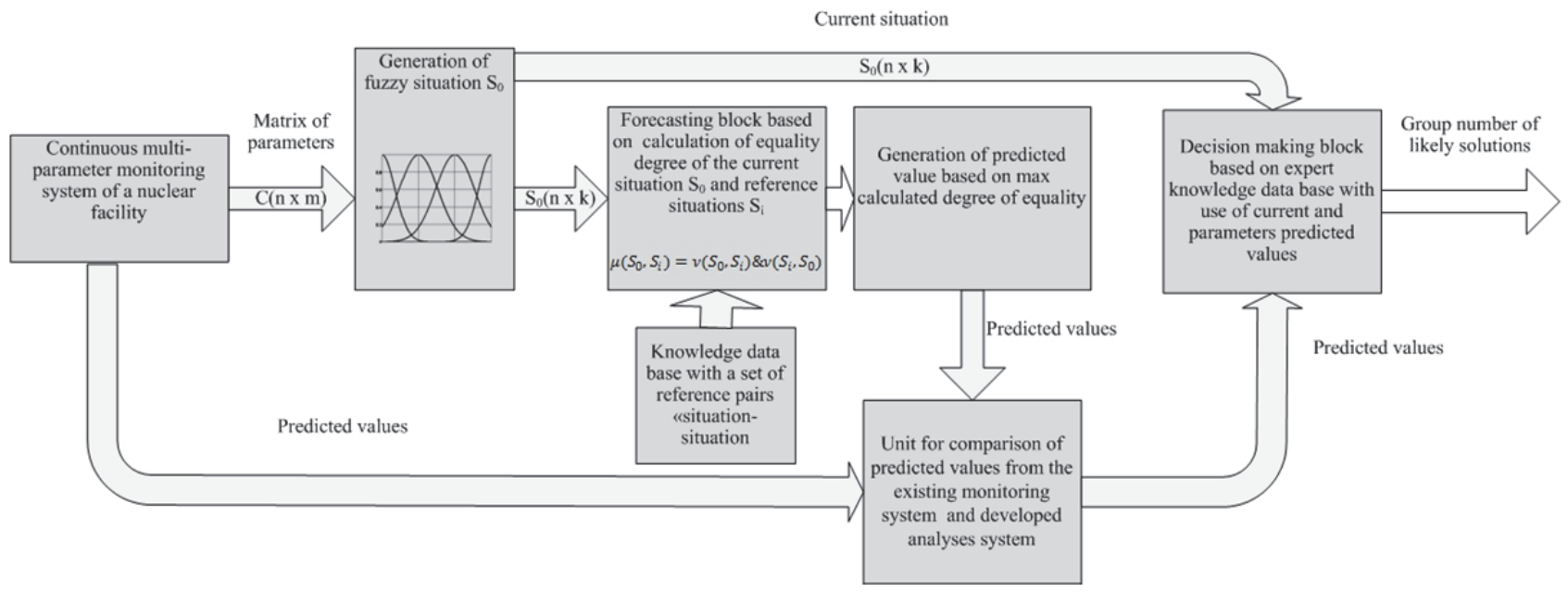

Fig. 2. Functional diagram of fuzzy situational model. 


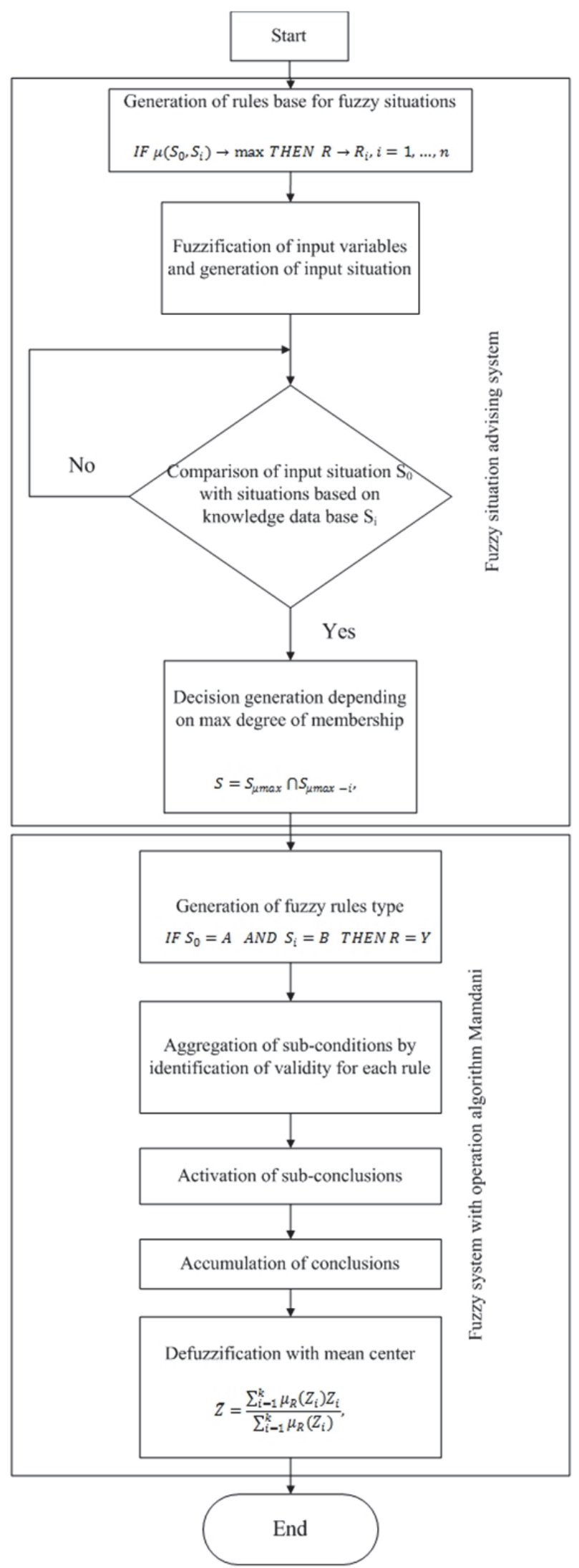

Fig. 3. Algorithm of decision making intellectulization.

\section{Conclusion}

The developed intellectual decision making system is a state-of-the-art tool for analyzing and forecasting status dynamics of hazardous technological facility. The main characteristic of the proposed integrated system is in implementation in the common format of two fuzzy systems together, serially communicating data without necessity of additional fuzzyfication-defuzzyfication.

\section{References}

1. V. Povarov, M. Bakirov, A. Danilov, Automatic system of multi-parameter monitoring of nuclear power installations status (Voronezh, Scientific book, 2017)

2. V. Burkovsky, K. Gusev, Voronezh technical university reporter, 3-1, 13-17 (2014)

3. D. Rutkovskaya, L. Rutkovsky, M. Pilinsky, Neural networks, genetic algorisms and fuzzy systems (Moscow, Hot line-telecom, 2003)

4. S. Ayvazyan, I. Eniukov, L. Meshalkin, Applied statistics and research dependencies (Moscow, Finance and statistics, 1985)

5. K. Tanaka, H.O. Wang, Fuzzy control systems design and analysis: a linear matrix inequality approach (Wiley-Interscience, John Wiley and Sons, 2001)

6. N. Yarushkina Fundamentals of the theory of fuzzy and hybrid systems (M., Finance and statistics, 2004)

7. K. Jacek, Analytical Methods in Fuzzy Modeling and Control (Springer, 2009) 